Revista Perspectiva Online: Humanas \& Sociais Aplicadas Dezembro de 2017, Vol.7, no 20, p.11-27

ISSN: 2236-8876 (Online)

DOI: $10.25242 / 887672020171545$

\title{
DESVALORIZAÇÃO DO TRABALHO DOCENTE BRASILEIRO: UMA REFLEXÃO DE SEUS ASPECTOS HISTÓRICOS
}

\author{
Viviana Patricia Kozlowski Lucyk ${ }^{1 *}$ \& Edilene Hatschbach Graupmann
}

\section{RESUMO}

LUCYK,V.P.K, GRAUPMANN,E.H. Desvalorização do Trabalho Docente Brasileiro: Uma Reflexão de seus Aspectos Históricos. Perpectivas Online: Humanas \& Sociais Aplicadas, v.7, n.20, p.11-27, 2017.

Esta proposta de estudo pretende abordar o tema da desvalorização do trabalho docente. Nesse ínterim, busca-se entender como ocorreu a desvalorização da classe docente no Brasil e quais os principais fatores que contribuíram para esse processo. Com base nisso, os objetivos e interesses de pesquisa estão ligados à reflexão sobre a situação atual dos professores, considerando as tendências pedagógicas da educação brasileira, o contexto histórico e as mudanças sociais que causaram a transformação no trabalho docente e o desprestígio de sua imagem perante a sociedade. Historicamente, a educação é de fundamental importância para o desenvolvimento do homem e é vista, nos dias atuais, como principal via de acesso ao desenvolvimento socioeconômico de um país. A metodologia da pesquisa é do tipo teórico bibliográfico. No decorrer da pesquisa verificarse-á quais são os principais fatores que contribuíram para o processo de desvalorização da classe docente no Brasil, com ênfase à proletarização da profissão, à massificação da educação e à inserção das mulheres no quadro docente.

Palavras-chave: Professor. Profissão. Desvalorização Docente. 


\begin{abstract}
:
This study proposal intends to address the theme of the devaluation of teaching work. In the meantime, it seeks to understand how the devaluation of the teaching class occurred in Brazil and what were the main factors that contributed to this process. Based on this, research objectives and interests are linked to reflection on the current situation of teachers, considering the pedagogical tendencies of Brazilian education, the historical context and the social changes that caused the transformation in the teaching work and the lack of prestige of its image before the

society. Historically, education is of fundamental importance for the development of man and is nowadays seen as the main way of access to the socioeconomic development of a country. The methodology of the research is of the theoretical bibliographic type. In the course of the research, it will be verified what are the main factors that contributed to the process of devaluation of the teaching class in Brazil, with emphasis on the proletarianization of the profession, the massification of education and the insertion of women in the teaching staff.
\end{abstract}

Keywords: Professor. Profession. Teacher Devaluation.

1 Mestranda em Educação Universidade Estadual do Centro-Oeste -UNICENTRO- R. Salvatore Renna, 875, Santa Cruz, Guarapuava, PR, CEP:85015-430, Brasil;

2 Universidade Estadual do Paraná, Campus de União da Vitória- UNESPAR/UV-Praça Coronel Amazonas, Centro,União da Vitória, PR,CEP:84600000 ,Brasil.

(*)e-mail: vivipk23@yahoo.com.br

Data de chegada: 07/04/2017 Aceito para publicação: 30/10/2017

Persp. online: hum. \& sociais aplicada., Campos dos Goytacazes, 20 (7), 11-27, 2017

seer.perspectivasonline.com.br 


\section{INTRODUÇÃO}

A presente pesquisa tem como máxima direcional uma discussão concatenada à desvalorização do trabalho docente, tendo em vista que é preocupante o cenário de decadência e desprestígio em que a profissão docente se encontra.

Observamos, no bojo da crise na educação, a centralidade do/a professor/a. Indubitavelmente, a cobrança de resultados recai sobre o/a docente, que deve dar conta de inúmeras atribuições, as quais tendem a ir além daquilo que é pertinente à sua formação. Nesse tocante, atribui-se à figura do/a educador/a a responsabilidade pela maioria dos problemas correlacionados ao sistema educacional.

É mister afirmarmos que a educação é de fundamental importância ao desenvolvimento do homem, sendo concebida enquanto principal via de acesso ao progresso socioeconômico de um país. Contrariando o esperado, ao mesmo tempo em que a educação é apontada como elemento de basilar relevância, também sofre um substancial desprestígio da sociedade. Frente a isso, o/a professor/a, da mesma forma que a educação, vem sofrendo um constante desrespeito social e financeiro, atuando em péssimas condições e longas jornadas de trabalho.

Pelo exposto, compete-nos ressaltar que essas são apenas algumas das problemáticas com as quais a classe docente se depara nos dias de hoje. Assim, por meio de pesquisa bibliográfica, este trabalho tem, como pretensão-mor, tecer considerações sobre a situação atual dos educadores, atentando às tendências pedagógicas da educação brasileira, ao contexto histórico e às mudanças sociais que causaram a transformação no trabalho docente e a deterioração da sua imagem perante a sociedade, pois muitos acreditam que é uma profissão que "ganha-se bem" e este discurso vem expandindo-se historicamente.

Ao iniciar a pesquisa, percebemos que o tema é novo entre os pesquisadores, caso consideremos que este começou a ser estudado nos últimos 20 anos. Assim, iniciamos uma busca em diversos livros; no entanto, não encontramos um autor específico que abordasse apenas esse tema. Diante deste fato, foi necessário um longo período de leituras, onde encontrávamos em cada livro um pedacinho importante para nossa temática. Em meio à pesquisa, destacamos os textos de Michael Apple, um autor norte-americano, que em seu livro Educação e Poder faz uma abordagem a respeito da crise e da mercantilização da educação, na qual o professor se encontra como ponto central do processo. A crise na educação é discutida também por Pablo Gentilli, autor argentino que, na obra Desencanto e Utopia: A educação no labirinto dos novos tempos, discute o tema sob uma perspectiva neoliberal, de modo que a educação faz parte de discursos onde a escola é vista como salvacionista e quando esta escola não dá conta de todos os problemas sociais, a cobrança recai sobre a figura do professor. Nossas discussões envolvem a crise da educação devido a indissociável ligação da figura do professor aos resultados da educação e por ser um ícone fundamental do processo educacional.

Fazem parte de nossa pesquisa bibliográfica, diversos autores envolvidos com as questões educacionais, com a formação de professores, com a história e filosofia da educação e com a imagem do professor e de sua profissão, como é o caso de Miguel Arroyo, José Carlos Libâneo, António Nóvoa, Gimeno Sacristán, Jacques Delors, Paulo Freire, Vitor Henrique Paro, Maria Lucia de Arruda Aranha, Mariano Fernandes Enguita, Maurice Tardif e Claude Lessard que corroboram conosco na compreensão a respeito da hipótese da desvalorização do trabalho docente brasileiro.

Persp. online: hum. \& sociais aplicada., Campos dos Goytacazes, 20 (7), 11-27, 2017

seer.perspectivasonline.com.br 


\section{METODOLOGIA}

A pesquisa em ciências humanas tem se caracterizado pela necessidade de interpretação dos dados da realidade (MINAYO, 1998). Trata-se de definir um caminho metodológico que permita a profunda compreensão do tema investigado.

Dessa forma, para atingir os objetivos, a metodologia de pesquisa a ser utilizada é de caráter teórico bibliográfica, de cunho qualitativo, onde as seguintes técnicas e instrumentos de pesquisa são delineadores: leitura, análise e interpretação de textos.

De acordo com Tozoni-Reis (2010), a pesquisa qualitativa é uma modalidade segundo a qual a compreensão dos conteúdos é mais importante do que sua descrição ou explicação. Portanto, nas ciências humanas é mais necessário desvendar os significados mais profundos do observado do que o imediatamente aparente.

A pesquisa bibliográfica se caracteriza pelo fato de que o campo onde será feita a coleta de dados é a própria bibliografia sobre o tema que se pretende investigar. Assim, na pesquisa bibliográfica vamos buscar, nos autores e obras selecionados, os dados para a produção do conhecimento pretendido. Porém, é notório destacar que os procedimentos metodológicos da pesquisa bibliográfica são bastante característicos. A leitura, para análise e interpretação dos dados, e a atividade específica em todo processo, e exige do pesquisador maturidade e disciplina.

A primeira etapa voltou-se à da coleta de dados através da leitura analítica que, conforme Severino (1985), é um método de estudo de texto de natureza teórica, que visa fornecer uma compreensão global do significado das ideias dos autores sendo os processos básicos: análise textual, análise temática, análise interpretativa, problematização e síntese pessoal. Desta forma, os autores e as obras foram analisados à luz de fichamentos bibliográficos, onde o foco norteador recaiu sobre as informações completas sobre o autor e obra, informações do contexto histórico da produção da obra, o resumo do conteúdo, identificação do objetivo, identificação da tese, identificação do referencial teórico, dados sobre as fontes e referências utilizados pelo autor. Assim, por meio dos fichamentos, torna-se possível sistematizar a coleta de dados para análise do estudo.

A segunda etapa se baseou na organização dos dados coletados em categorias a serem analisadas. Posteriormente, foi principiada a análise e interpretação dos dados. Segundo Severino (1985), interpretar é tomar uma posição própria a respeito das ideias apresentadas, é superar a estrita mensagem do texto, é ler nas entrelinhas é explorar as ideias expostas, enfim, é dialogar com o autor.

Por fim, na terceira etapa, deu-se a elaboração de um texto apresentando argumentações sobre como ocorreu o possível processo de desvalorização docente no Brasil, respaldando-se nos subsídios teóricos.

Persp. online: hum. \& sociais aplicada., Campos dos Goytacazes, 20 (7), 11-27, 2017

seer.perspectivasonline.com.br 


\section{RESULTADOS}

A princípio, é interessante que recorramos à contextualização descrita por Sacristán (1995, p. 64), no que compete ao que se espera do professorado:

o debate em torno do professorado é um dos polos de referência do pensamento sobre a educação, objeto obrigatório da investigação educativa e pedra angular dos processos de reforma dos sistemas educativos. Grande parte dos problemas e dos temas educativos conduzem a uma implicação dos professores, exigindo-lhes determinadas actuações, desenhando ou projectando sobre a sua figura uma série de aspirações que se assumem como uma condição para a melhoria da qualidade da educação.

Tornou-se uma prática comum impor ao/à educador/a a imprescindibilidade de dar conta de inúmeras atribuições, dentro e fora de sala de aula. Concomitantemente, recai sobre eles/elas a culpa por tudo aquilo que não funciona corretamente no sistema educacional. Dialogando com o exposto, Gentili (2008, p. 47) ressalta que:

o quadro se torna ainda mais dramático quando observamos a ofensiva ideológica conservadora lançada contra os professores nos últimos anos. Eles são responsabilizados pela profunda crise dos sistemas escolares e lhes é atribuída a culpa pelas péssimas condições de aprendizagem dos alunos e alunas, pelas altas taxas de repetência, pelas escassas oportunidades de inserção no trabalho para os recém-saídos do sistema escolar, pela violência dentro e fora das escolas e pela falta de participação cidadã nas questões mais relevantes que nossas sociedades devem enfrentar.

Quando mencionamos que a educação é base para toda e qualquer mudança no país, estamos compactuando com as ideias de Libâneo (2003, p. 95), que relaciona à necessidade do capital a confiança na educação "a competitividade instalada e requerida pelo capital transnacional passa, cada vez mais, pelo desenvolvimento do conhecimento e pela formação de recursos humanos, atribuindo papel central à educação".

Por outra via, Libâneo (2010, p. 172) reitera que "nunca se falou tanto da valorização da educação, do magistério, e nunca a atividade pedagógico-docente foi tão desvalorizada, especialmente a partir das políticas públicas”.

Nessa mesma linha argumentativa, Gentili $(2008$, p. 17) é taxativo ao argumentar que não cabe à escola a missão de salvar o mundo sozinha:

a educação, não dispõe da química necessária para mudar o mundo, embora possa contribuir com a formação dos corações e mentes daqueles e daquelas que se disponham a lutar para fazer dele um espaço mais humano, mais justo e solidário, mais digno e igualitário. Carlos Rodrigues Brandão disse uma vez: "A educação não transforma a sociedade, mas, talvez, possa mudar as pessoas, e por isso ela vale a pena”. A educação constitui nossa oportunidade de aprender juntos a interpretar o mundo, compreendê-lo; nossa possibilidade de compartilhar uma experiência de aprendizagem, onde convivam e se enriqueçam múltiplos olhares, múltiplos sentidos e intermináveis respostas sempre inconclusas; nossa oportunidade de lutar pela socialização do acesso ao saber historicamente acumulado e socialmente produzido, evitando assim seu monopólio privado e a alienação de seus benefícios;

Persp. online: hum. \& sociais aplicada., Campos dos Goytacazes, 20 (7), 11-27, 2017

seer.perspectivasonline.com.br 
Paro (1986, p. 111-144), por sua vez, também reforça esta ideia, de que a função da escola não é salvacionista, "a escola, na verdade, não possui de modo nenhum esse poder de corrigir as injustiças provocadas pela ordem capitalista". E complementa afirmando "a escola é apenas uma das instâncias em que se realiza a educação que o aluno desenvolve durante sua vida".

Ainda de acordo com as discussões, Tardif e Lessard (2005, p. 282) pontuam que a sociedade deposita, exponencialmente, expectativas com relação ao ensino. Logo, "a educação é vista cada vez mais como um remédio para os problemas da sociedade assalariada e às transformações da economia". Diante das observações elencadas, o dizer de Gentilli (2008, p. 219) dá-nos a síntese da problemática "a forma mais cínica de confirmar o fracasso de uma instituição é exigir que ela faça aquilo que não deve ou não pode fazer".

É notório que não nos resta dúvida de que o papel docente é basal para a sociedade e, de acordo com Sacristán (1995, p. 67), são "frequentes as declarações sobre a importante missão que lhes incumbe". Porém, a classe professoral "tem sido abalada por todos os lados: baixos salários, deficiências de formação, desvalorização profissional implicando baixo status social e profissional, falta de condições de trabalho, falta de profissionalismo etc." (LIBÂNEO, 2010, p. 25).

Delineado esse quadro, se faz necessária uma análise sucinta do contexto da educação brasileira, onde se incluem as tendências pedagógicas que se fizeram e se fazem presentes nas escolas. Nesse preâmbulo compositivo, destacamos a Pedagogia Tradicional, a Escola Nova, a Tendência Tecnicista, a Pedagogia Libertadora e a Pedagogia Histórico-crítica, por meio das quais buscamos compreender como estas influenciaram na transformação do trabalho docente, bem como identificar em que período é que teve início a desvalorização docente.

No âmago das tendências pedagógicas, comecemos com a Escola Tradicional, principiada, no Brasil, com a chegada dos padres jesuítas, predominando no cenário educacional do século XVI ao século XX. Nesta tendência, de acordo com Aranha (2006), o/a professor/a organiza o conteúdo a ser ministrado, ao passo que deve ser o detentor de todo o saber. Graças ao laborioso domínio conteudístico, a transmissão ao alunado pautava-se (e pauta-se, diga-se de passagem) na premissa de tudo que era explanado configurava-se enquanto verdade absoluta, isenta de questionamentos. Diante disso, o/a educador/a atenuava o princípio da interação, dando materialidade a uma pedagogia que visualizava o discente apenas como um ser passivo e receptivo. De igual modo, o/a professor/a passa a ser visto como o centro do processo, fazendo contínuo uso do método expositivo, essencialmente baseado em exercícios, em repetições e memorização de conceitos e fórmulas.

No tocante à Escola Nova, Aranha (2006) relata-nos que esse movimento tem por intencionalidade a renovação do ensino, tendo início em solo brasileiro na primeira metade do século XX, onde a figura central foi Anísio Teixeira, que se encarregou de difundir o ideário escolanovista. O auge ocorre em 1932, com a divulgação do Manifesto dos Pioneiros da Educação Nova, que buscava a universalização da escola pública, laica e gratuita. Na tendência supracitada, a função do/a professor/a é de facilitador/a, que age como estimulador/a e orientador/a da aprendizagem, cuja iniciativa principal caberia aos próprios alunos. Sob esse enfoque, o educando é visto enquanto um ser ativo, sendo que a aprendizagem aconteceria de forma espontânea, em decorrência ao ambiente estimulante e à relação viva que se estabeleceria entre alunos e entre estes e o educador.

Persp. online: hum. \& sociais aplicada., Campos dos Goytacazes, 20 (7), 11-27, 2017

seer.perspectivasonline.com.br 
Concatenado ao exposto, na década de 1960 começam a aparecer propostas baseadas no tecnicismo empresarial. Embasando-nos em Aranha (2006), percebemos que com a aceleração da industrialização, o sistema de ensino atual não supria a necessidade de recursos humanos, necessários ao desenvolvimento econômico. Frente a isso, é com o golpe militar de 1964 e com os acordos MEC-Usaid, que nosso país passa a implantar o Tecnicismo, que visa a resolver esse problema, inserindo na escola o modelo empresarial. Dessa forma, Aranha (2006, p. 231) verifica que ocorre "a divisão de tarefas entre os diversos técnicos de ensino incumbidos do planejamento racional do trabalho educacional".

Consequentemente, o cenário que começa a se delinear calca-se na burocratização do ensino, onde a classe professoral fica encarregada de preencher detalhados relatórios. Sacristán (1995, p. 72), por sua vez, sublinha o quanto que essa burocratização é prejudicial à profissão docente:

uma prática burocraticamente controlada dá origem a um sistema de dependência dos profissionais relativamente às directrizes exteriores, de modo que os problemas que os docentes detectam e têm de resolver são, sobretudo, problemas de adequação/conflito com essas condições estabelecidas (legais, curriculares, organizativas, etc).

A esse respeito, Nóvoa (1995, p. 25) requer a nossa atenção ao controle essencialmente burocrático exercido pelos órgãos superiores do sistema.

[...] a presença estatal no âmbito do ensino é importante, nomeadamente para assegurar uma equidade social e serviços de qualidade, mas o seu papel de supervisão deve exercer-se numa lógica de acompanhamento e de avaliação reguladora, e não numa lógica prescritiva e burocracia regulamentadora. Esta mudança de atitude coloca a profissão docente perante desafios inadiáveis, aos quais os professores e as suas organizações não têm sabido responder com criatividade.

Com efeito, o papel do/a professor/a, conforme Libâneo (2008, p. 30), passa a ser somente "administrar as condições de transmissão da matéria, conforme um sistema instrucional eficiente". Diante disso, a responsabilidade docente é reduzida à transmissão de conteúdo, extenuando a autonomia professoral e inferiorizando a profissão. Por essa razão, observamos que a Tendência Tecnicista tem por desígnio cardeal modelar o comportamento humano por meio de técnicas específicas.

Intentando dar continuidade às discussões, passemos à Pedagogia Libertadora de Paulo Freire. Libâneo (2008) nos dá a dimensionalidade da tendência ao pontuar que uma das principais características desta é sua atuação não-formal; tendo em vista que ela não se utiliza dos conteúdos tradicionais, de modo que busca, junto aos educandos, os chamados "temas geradores", que são motes provenientes da vida prática. De uma maneira geral, a Pedagogia Libertadora tem por objetivo questionar "a realidade das relações do homem com a natureza e com os outros homens, visando a uma transformação" (LIBÂNEO, 2008, p. 33).

O/a docente, segundo Libâneo (2008), utiliza, essencialmente, como método o diálogo e é visto apenas como coordenador de debates, que estabelece uma relação horizontal, adaptando-se às

Persp. online: hum. \& sociais aplicada., Campos dos Goytacazes, 20 (7), 11-27, 2017

seer.perspectivasonline.com.br 
características e necessidades do discente, que é sujeito participante no grupo, onde o autoritarismo por parte do/a professor/a é inexistente.

Por fim, eis que emerge, na década de 1970, a Pedagogia Histórico-crítica, tendo como principal articulador Dermeval Saviani. Nesse ínterim, Aranha (1996, p. 219) destaca que a tendência mencionada "se insere na tentativa de reverter o quadro de desorganização que torna uma escola excludente, com altos índices de analfabetismo, evasão, repetência e, portanto, de seletividade".

De acordo com Libâneo (2008, p. 39), a finalidade da instituição escolar, na Pedagogia Histórico-crítica, tem por base a "preparação do aluno para o mundo adulto e suas contradições, fornecendo-lhe um instrumental, por meio da aquisição de conteúdos e da socialização, para uma participação organizada e ativa na democratização da sociedade".

Ainda conforme o autor supracitado, a figura docente é autoridade competente, que direciona o processo pedagógico, ao passo que interfere e cria condições necessárias à apropriação do conhecimento. Enquanto especificidade da relação pedagógica, é o mediador entre os saberes e o discente. Importante sinalizar que o aluno é um ser ativo no processo de aprendizado.

Em meio ao cenário ilustrado, constatamos que as tendências pedagógicas têm grande influência no cenário educacional brasileiro. Indubitavelmente, dentro do contexto histórico da implantação da Tendência Tecnicista, que tem início o processo de desvalorização do papel do/a professor/a. Assim, verificamos, segundo Libâneo (2003), que a Lei $\mathrm{n}^{\mathrm{o}}$ 5.692/71, ao ampliar a escolaridade mínima para oito anos e tornar profissionalizante e obrigatório o ensino de segundo grau, teve sua parcela de culpa no processo da possível desvalorização docente.

A expansão da oferta de vagas, nos diversos níveis de ensino, teve como consequência o comprometimento da qualidade dos serviços prestados, em razão da crescente degradação das condições de exercício do magistério e da desvalorização do professor. (LIBÂNEO, 2003, p. 144).

Portanto, a partir da promulgação da Lei ${ }^{0}$ 5.692/71, é que se enceta a massificação do ensino ocorrido após a Revolução Industrial, pois as fábricas necessitavam, de acordo com Aranha (2006), de mão de obra mais qualificada, de trabalhadores que soubessem ler, escrever e contar.

Dessa forma, eis que vem à tona a urgência latente de mais professores para dar conta da demanda educacional. Em contrapartida, como na época não havia um número suficiente de profissionais qualificados, implanta-se um determinado programa educacional, elaborado por especialistas, onde a função do/a professor/a era a de apenas aplicar este programa, competindo garantir, no alunado, a fixação do conteúdo. Em decorrência a isso, passaram a ser admitidos docentes com o mínimo de formação. Consequentemente, segundo Aranha (2006, p. 234), essa prática acabou "tornando os professores meros técnicos repetidores de pacotes pré-elaborados". Diante desse contexto, Apple (2002, p. 161) considera que "à medida que os procedimentos de controle técnico entram na escola sob o disfarce de "sistemas" pré-planejados de currículo, ensino e avaliação, os professores estão sendo desqualificados". Além disso, Sacristán (1995, p. 72) complementa 
o posto de trabalho dos professores está muito marcado por tendências que afectam todo o sistema, tais como o progresso da especialização, uma maior pormenorização das destrezas de ensino, uma maior fragmentação da educação, o desenvolvimento de mecanismos de supervisão e avaliação, etc. (Lawn, 1989). A caracterização técnica dos currículos, a sua elaboração prévia por especialistas e uma maior regulamentação da actividade pedagógica, constituem factores de desprofissionalização do professorado. Apple (1989) acrescenta a estes factores a intensificação do trabalho docente, com uma sobrecarga de actividades relacionadas, direta ou indirectamente, com o ensino, a avaliação, a gestão, etc.

Outra questão importante a ser exteriorizada é que neste período surgem os livros didáticos. Tal surgimento implica na perda da autonomia professoral, tendo em mente que o educador passa a não ter a liberdade de planejamento da aula, devendo apenas seguir o conteúdo elaborado por especialistas, sem espaço para ir além e suscitar discussões. Naturalmente, não há o diálogo e nem afetividade entre professor/a e corpo discente. Somando às limitações impositivas, ainda temos a exclusão, no currículo, de acordo com Aranha (2006, p. 234), da disciplina de "filosofia e a minimização da literatura, da história, da geografia humana e das artes".

Outro fator que pode contribuir para a desvalorização do trabalho docente, conforme assevera Sacristán (1995), pautou-se no detalhe de que a massificação do ensino e a ampliação das responsabilidades dos/as professores/as não tiveram o respaldo efetivo de investimentos materiais e da melhoria das condições trabalhistas. Para Libâneo (2003), a falta de compromisso do estado com a educação pública foi responsável pela deterioração dos salários dos educadores, ao passo que gerou péssimas condições de trabalho, provocando greves.

Sacristán (1995, p. 66-67) elenca-nos seis fatores que são os causadores do desprestígio da profissão docente:

1) A origem do grupo, que provém das classes média e baixa. 2) O tamanho do grupo profissional que, por ser numeroso, dificulta a melhoria substancial do salário. 3) A proporção de mulheres, manifestação de uma selecção indirecta, na medida em que as mulheres são um grupo socialmente discriminado. 4) A qualificação acadêmica de acesso, que é de nível médio para os professores dos ensinos infantil e primário. 5) O status dos clientes. 6) A relação com os clientes, que não é voluntária, mas sim baseada na obrigatoriedade do consumo do ensino.

A partir dos motivos citados, procuraremos analisar como ocorreu o possível processo de desvalorização social da classe docente no Brasil. Assim, pontuaremos acerca das principais causas que contribuíram para esse cenário depreciativo:

a) Observamos, de acordo com Sacristán (1995, p. 72), considerações pertinentes sobre a perda da autonomia professoral:

as ideias acerca da autonomia dos professores obscurecem, muitas vezes, o contexto real da acção docente. De um modo geral, os discursos sobre os professores esquecem que as margens de autonomia estão balizadas por questões políticas e históricas, que condicionam o diálogo entre a teoria e a prática. As abordagens retóricas, nomeadamente as perspectivas progressistas que sublinham as resistências dos professores à mudança, esquecem-se muitas vezes de exigir uma mudança das condições profissionais e ideológicas em que a atividade docente se realiza. (SACRISTÁN, 1995, p. 72).

Persp. online: hum. \& sociais aplicada., Campos dos Goytacazes, 20 (7), 11-27, 2017

seer.perspectivasonline.com.br 
Nesse tocante de atenuação autônoma, Enguita (1991, p.48-49) considera o livro didático como um fator agravante no que compte à desqualificação do professor, quando diz que:

para este processo contribuem também os fabricantes de livros-didáticos e outras mercadorias educacionais. O livro-didático especifica para o professor o conjunto de conhecimentos que deverá transmitir a sequência dos mesmos e a forma de transmiti-los e organizá-los. Ainda que de menor repercussão no conjunto da vida escolar, um efeito similar têm outros recursos docentes, como os programas informatizados ou os chamados "pacotes curriculares".

$\mathrm{Na}$ mesma perspectiva, Apple (1995, p. 160-161) argumenta que a escola, com a introdução de softwares pré-empacotados, tornou-se um mercado lucrativo. No entanto, a incorporação dessas tecnologias desencadeia, segundo o mesmo autor, "desqualificação" e perda de poder dos/as professores/as.

Também é notório, nesse panorama, o papel desempenhado pela sociedade, que não separa a crise da educação da figura docente. Ao contrário, culpa acirradamente o/a professor/a, aumentando o desprestígio deste.

A profissão docente é socialmente partilhada, o que explica a sua dimensão conflituosa numa sociedade complexa na qual os significados divergem entre grupos sociais, econômicos e culturais. A escola apresenta-se muitas vezes como uma instituição obsoleta aos olhos de agentes e forças culturais que necessitam de uma outra educação e que, portanto, tendem a pôr em causa a legitimidade dos professores, contribuindo para a sua desprofissionalização. Por isso, toda a mudança educativa deve assumir-se, em primeiro lugar, como uma mudança cultural. (SACRISTÁN,1995, p. 71).

b) Outro fator da mais alta importância, como bem ressalta Nóvoa (1995), é a questão da formação do/a educador/a que, certamente, é a área mais frágil das mudanças no âmbito do ensino, tendo em vista que ali não se formam somente profissionais, mas se constrói uma profissão. O processo formativo desse profissional deve acompanhar as mudanças da sociedade e ter uma base sólida. Logicamente, a mudança no cenário educativo

[...] tem de ser explicada mais a partir de modelos antropológicos e culturais do que a partir de esquemas de inovação tecnológica. A formação contínua de professores deve pôr em causa as bases da profissionalidade docente, não se limitando a uma reciclagem ao nível dos conteúdos ou das destrezas. [...] A mudança pedagógica e o aperfeiçoamento dos professores devem ser entendidos no quadro do desenvolvimento pessoal e profissional. (SACRISTÁN, 1995, p. 75).

Interessante frisar que outros autores fazem menção ao mesmo aspecto, como Aranha (2006, p. 43), que comenta "a revalorização da profissão docente deve começar pelos cuidados com a formação do professor". Em diálogo, Nóvoa (1995, p. 26) complementa: 
por outro lado, a formação de professores precisa de ser repensada e reestruturada como um todo, abrangendo as dimensões da formação inicial, da indução e da formação contínua (Hargreaves, 1991). Os modelos profissionais de formação de professores devem integrar conceptualizações aos seguintes níveis: (1) contexto ocupacional; (2) natureza do papel profissional; (3) competência profissional; (4) saber profissional; (5) natureza da aprendizagem profissional; (6) currículo e pedagogia" (Elliott, 1991.310). [...]

Em linha de raciocínio similar, Delors (2003, p. 160) empreende uma reflexão a respeito da importância da formação contínua, destacando que "a qualidade de ensino é determinada tanto ou mais pela formação contínua dos professores do que pela sua formação inicial”.

Diante do exposto, verificamos a essencialidade de termos um investimento mássico em formação continuada, caso queiramos alcançar a merecida qualidade do ensino que a nossa sociedade em desenvolvimento necessita. Lembremo-nos, a título de esclarecimento, de que as tecnologias da comunicação e informação, juntamente com as mudanças sociais, evoluem num ritmo extremamente rápido e exigem dos/as professores/as uma capacitação para acompanhar essas mudanças.

Para Libâneo (2003, p. 277) é fundamental tecer um breve comentário sobre a indiferença com que a política educacional visualiza a situação da formação docente: "a legislação em vigor permite que profissionais de outras áreas se dediquem à educação, frequentando curso de formação pedagógica de apenas 540 horas". Sob esse viés, consideramos inadmissível deixar que profissionais de outras áreas atuem na educação, pois, de acordo com Libâneo (2003, p. 277-278), "certamente, atuarão na área educacional não como opção de tempo integral, conhecendo e vivendo suas especificidades profissionais, mas como um 'bico' para uma situação de desemprego ou até que consigam ocupação mais vantajosa".

No tocante a este ponto de vista, Arroyo (2000, p. 22-23) cita o exemplo da campanha Amigos da Escola, lançada pelo governo, que se caracteriza em mais um fator de desprofissionalização, tendo em vista que "a educação escolar tratada como uma terra vadia, sem cercas, facilmente invadida por aventureiros ou por amigos. Qualquer um entende, palpita sobre a escola, aceita ser professor(a), secretário(a) de educação". Assim, Arroyo (2000, p. 23) assinala que a legislação, ao admitir que "qualquer um que domine um conhecimento e uma técnica, poderá ensiná-los como um biscate e um complemento a seus salários", está contribuindo para a potencialização desse horizonte cinzento.

Arroyo (2000) volta a contribuir, salientando que apesar dos níveis de qualificação em graduação e pós-graduação dos professores brasileiros ter crescido muito nas últimas décadas, seu estatuto profissional permanece indefinido.

Considerando as afirmações acima, pode-se perceber que a formação de professores é mais uma das áreas que sofre com o descaso do governo, com a falta de investimentos, com a política de formação. Afinal, conforme lamenta Libâneo (2003, p. 154) "a priorização da educação tem estado presente mais no discurso que nas ações”. 
c) No Brasil a demanda por educação aumenta a cada ano e junto cresce o número de docentes para dar conta desta amplitude. Simultaneamente, é necessário considerar, segundo Paro (2010), que a grande maioria desses docentes tem que trabalhar em mais de uma instituição para complementar sua renda, prejudicando, assim, a qualidade de seu trabalho. Dessa forma, percebemos que este fato constitui-se em uma das principais causas da desvalorização da classe professoral, visto que comparada com outras profissões, sua remuneração é bem inferior. Nóvoa (1995) aponta como um dos elementos que contribuem para essa desvalorização salarial, o fato de que os/as professores/as integram um dos grupos profissionais mais amplos da sociedade atual.

Na mesma perspectiva, Libâneo (2010, p. 107) identifica como relevante o seguinte tópico "o descaso com que a educação é tratada pelos governos, cujas consequências se refletem nos salários, na carreira, na formação do magistério;”. Paro (2010) direciona a nossa atenção a outros problemas, relacionados diretamente à falta de investimento do governo, como as condições precárias do trabalho dos educadores, contemplando, nesse bojo depreciativo, edifícios escolares e equipamentos deteriorados, classes abarrotadas, falta de segurança nas escolas e escassez de recursos de toda ordem. Gentili (2008, p. 45), por sua vez, relata-nos que este assunto é bem mais abrangente do que a princípio pode parecer, envolvendo múltiplas questões:

\begin{abstract}
a precariedade salarial está associada, assim, à progressiva precariedade das condições de trabalho pedagógico nas escolas. O baixo investimento em educação resulta em péssimas condições de infra-estrutura escolar, falta de material didático apropriado, ausência de bibliotecas e, como vimos, em salas de aula superlotadas. Os governos neoliberais tentaram atenuar essa situação mediante programas de modernização periférica que fizeram da chamada "transformação educacional" uma verdadeira caricatura do que deveria ser uma política pública democrática: compra de alguns poucos computadores, instalação de antenas parabólicas e aparelhos de vídeo, fax e data shows em escolas com goteiras permanentes, sem saneamento básico, com um único banheiro para meninos e meninas, muitas vezes sem giz e até mesmo sem energia elétrica.
\end{abstract}

Com relação ao ponto delineado, Libâneo (2010, p. 172) afirma, claramente, que a classe professoral encontra-se em uma situação de calamidade: "a remuneração de professores caiu sensivelmente, levando a uma degradação sem precedentes do exercício profissional;". Ocasionando, dessa maneira, o êxodo de inúmeros/as educadores/as para outras profissões, oferecedoras de uma remuneração mais elevada. Paro (2010, p. 95-96) argumenta que a discussão sobre o assunto, certamente, precisaria levar em conta que:

numa economia de mercado, quando cai a remuneração por determinada ocupação, ocorre, como consequência imediata, uma cadeia de fatores que leva à queda da qualidade da força de trabalho a ela associada. Uma das primeiras ocorrências é a evasão das pessoas mais bem qualificadas, que investiram em sua formação e treinamento na expectativa de obter uma remuneração que tal ocupação já não mais oferece. Com o tempo, a ocupação só consegue atrair pessoas menos qualificadas, ou seja, aquelas que, por suas limitadas capacidades profissionais, não podem contar com melhores alternativas de emprego.

Podemos encerrar este tópico com as palavras de Paro (2010, p. 96), "ao pagar continuamente baixos salários, o sistema escolar demonstra contentar-se com o tipo de profissional de baixa qualificação com que tem contado". 
d) Identificamos como ponto relevante à ampliação da área de atuação do/a professor/a, bem como exigências que vão além de sua formação específica sobrecarregando o/a professor/a e descaracterizando sua atuação, conforme relata Sacristán (1995, p. 100):

\begin{abstract}
há um autêntico processo histórico de aumento das exigências que se fazem ao professor, pedindo-lhe que assuma um número cada vez maior de responsabilidades. No momento actual, o professor não pode afirmar que a sua tarefa se reduz apenas ao domínio cognitivo. Para além de saber a matéria que leciona, pede-se ao professor que seja facilitador da aprendizagem, pedagogo eficaz, organizador do trabalho de grupo, e que, para além do ensino, cuide do equilíbrio psicológico e afectivo dos alunos, da integração social e da educação sexual, etc; a tudo isto pode somar-se a atenção aos alunos especiais integrados na turma.
\end{abstract}

Com relação a isso, Libâneo (2003, p. 221) assevera que foram as reformas educacionais que provocaram diversas mudanças na profissão e na formação do/a docente. Assim, "por um lado, têm suas tarefas ampliadas, são muito mais exigidos, mas, por outro, nada lhes é oferecido em troca. A carreira continua apresentando as dificuldades existentes há muito tempo".

e) Finalmente, o último elemento que consideramos, nessa análise, é o ingresso da mulher no magistério, sendo caracterizado como um aspecto que contribuiu para a desvalorização docente. Nesse tocante, concede-se um destaque ao conceito de vocação para a introdução da mulher no magistério. Apple (1995, p. 60) investiga o fenômeno e relata que muitos autores defendiam a entrada da mulher no magistério devido suas características naturais, pontuando que "as mulheres não só eram professoras ideais para as crianças pequenas (devido sua paciência e jeito para cuidar), mas também que o magistério era a preparação ideal para a maternidade". Entretanto, o autor supramencionado explica que este fenômeno está relacionado à ideologia patriarcal, que vê o magistério como trabalho de mulher.

Freire (1997, p. 18-33) discute essa questão ao referir-se à forma de tratamento "tia", destinada às professoras como algo que inferioriza a profissão e a associa à questão ideológica, ao salientar "a tentativa de reduzir a professora à condição de tia é uma 'inocente' armadilha ideológica em que, tentando-se dar a ilusão de adocicar a vida da professora o que se tenta é amaciar a sua capacidade de luta" e conclui "quanto mais aceitamos ser tias e tios, tanto mais a sociedade estranha que façamos greve e exige que sejamos bem comportados".

Para compreendermos como ocorreu o fenômeno chamado feminização do magistério, alguns elementos importantes devem ser elencados: Primeiramente, essa visão de que ser professora é trabalho de mulher, vem de uma história bem distante, segundo enfatiza Apple (1995), e traz consigo algumas ideologias a respeito da domesticidade e do sentido de que a mulher tem um lugar próprio em que o magistério é explicado como uma extensão do trabalho doméstico. Essa visão também é identificada por Tardif e Lessard (2005, p. 176), quando relatam "existe como que uma continuidade entre o trabalho doméstico tradicionalmente feminino e essas pequenas tarefas efetuadas pela professora da escola primária”.

De acordo com Apple (1995, p. 59), "o magistério tornou-se feminino, em parte porque os homens o abandonaram. [...] Muitos professores ensinavam em tempo parcial ou como ponto de partida para outros empregos mais lucrativos". Todavia, com o aumento dos requisitos para lecionar, os homens foram aos poucos deixando o magistério, pois tinham facilidade de encontrar

Persp. online: hum. \& sociais aplicada., Campos dos Goytacazes, 20 (7), 11-27, 2017

seer.perspectivasonline.com.br 
emprego em outras áreas e os salários da docência passaram a ser inviáveis para se sustentar a família.

Apple (1995) indica, ainda, outros fatores que contribuíram para a feminização do magistério, como a luta das mulheres em busca de acesso à educação e ao trabalho remunerado. Eis, nesse viés direcional, o capitalismo, com suas numerosas fábricas, onde se fazia necessário grande número de funcionários; logo, as portas estavam abertas às mulheres, tendo em vista que elas aceitavam trabalhar por salários baixíssimos. Dentro dessas circunstâncias, as mulheres não tinham muitas opções: ou trabalhavam nas fábricas, local em que eram exploradas, ou em trabalhos domésticos. Logicamente, é assim que o magistério surge como uma opção atrativa aos olhos femininos.

De acordo com Apple (1995), a expansão do ensino também influenciou na entrada da mulher no magistério, pois com a necessidade de mais mestres, as mulheres aparecem como ótima solução para equilibrar o orçamento, com seus salários bem inferiores aos dos homens. Por outro lado, o trabalho da mulher era visto como algo temporário, onde ela iria se manter financeiramente até o casamento, premissa que justificava os baixos salários. Sob esse contexto, Apple (1995, p. 59) sublinha que o magistério passou a ser visto como um "símbolo de ascensão social para muitas mulheres". Dessa forma, elas recorriam ao Curso Normal, com a intencionalidade velada de conseguirem, posteriormente, um bom casamento. Contudo, Apple (1995) esclarece a questão sobre o "casamento", quando explica que esta não era uma preocupação das professoras que tinham o desejo de se casar, mas sim um medo expresso por suas famílias com relação ao futuro delas.

\section{DISCUSSÃO}

Considerando as ideias esboçadas acima, tentamos esclarecer as principais hipóteses que levaram à desvalorização da profissão docente, onde acreditamos ter atingido o objetivo da pesquisa, ao sintetizarmos os aspectos centrais considerados na análise bibliográfica desta problemática. Devemos, entretanto, assinalar que, possivelmente, nós professores fazemos parte de um grupo "desvalorizado socialmente", enfrentamos várias situações adversas no dia a dia de nosso trabalho, mas ao mesmo tempo devemos reconhecer nosso importante papel na sociedade e lutar para reconquistar nossa valorização, pois, de acordo com Delors (2003, p. 156):

o saber pode evidentemente adquirir-se de diversas maneiras e o ensino a distância ou a utilização de novas tecnologias no contexto escolar têm-se revelado eficaz. Mas para quase todos os alunos, em especial os que não dominam ainda os processos de reflexão e de aprendizagem, o professor continua indispensável.

O teórico citado agracia-nos com a seguinte constatação "a importância do papel do professor enquanto agente de mudança. Favorecendo a compreensão mútua e a tolerância, nunca foi tão patente como hoje em dia. Este papel será ainda, mais decisivo no século XXI". (DELORS, 2003, p. 153).

É possível perceber que alguns autores concordam com esta visão, como Tardif e Lessard (2005, p. 275), reiterando "a docência, como trabalho humano sobre seres humanos, constitui, no âmbito das sociedades modernas, uma atividade social fundamental". Visando a fechar com a dita

Persp. online: hum. \& sociais aplicada., Campos dos Goytacazes, 20 (7), 11-27, 2017

seer.perspectivasonline.com.br 
chave-de-ouro, recorremos às considerações pertinentes de Delors (2003, p. 190) "ensinar é uma arte e nada pode substituir a riqueza do diálogo pedagógico", ao passo que voltamo-nos aos dizeres sintetizadores de Arroyo (2000, p. 167): “os mestres-docentes têm um papel insubstituível”.

\section{CONCLUSÕES}

Tendo como base o arcabouço estudado, foi possível verificarmos que a desvalorização docente é um assunto novo entre os pesquisadores, caso consideremos que começou a ser estudado nos últimos 20 anos. Em outro âmbito, podemos supor que existem inúmeros fatores que contribuíram para essa desvalorização, mas seria uma tentativa amplamente complexa e fadada ao prolixo caso quiséssemos abordar todas. Assim, buscamos compreender os pontos que mais se destacam entre os pesquisadores do tema.

De igual modo, infere-se que a desvalorização salarial é um dos extremos abordados pelos estudiosos da área e que reflete diretamente na qualidade do ensino, pois se o professor se vê obrigado a dobrar ou triplicar sua jornada de trabalho para atingir uma remuneração digna, certamente o tempo com a preparação das aulas será prejudicado. Essa questão poderá ter reflexibilidade, também, na formação continuada, pois se o educador trabalhar diversos turnos para completar sua renda, não terá tempo para se dedicar à realização de cursos; ou, se não trabalhar, também não poderá fazer cursos, por falta de condições financeiras.

Em seguida, no âmago da desvalorização profissional, pode-se acrescentar a massificação da educação, a má qualidade na formação dos professores, a feminização do magistério e o aproveitamento da "mão de obra das estagiárias", que se submetem a trabalhar com uma remuneração baixíssima, as péssimas condições de trabalho, os escassos recursos disponíveis na escola, verificando a falta de políticas públicas eficientes, além de observarmos a abrangência da atuação profissional que exige dos professores a atuação em áreas em que eles não foram academicamente preparados.

Diante das leituras realizadas, a crise da profissão docente é bem antiga e para que esse quadro seja revertido, infere-se a necessidade de uma reforma educacional consistente, iniciando pela elaboração de políticas educacionais sólidas, bem como a revalorização do seu estatuto, a melhoria dos planos de carreira, o oferecimento de uma remuneração compatível ao seu nível de formação, o investimento na formação continuada de forma eficaz, e a melhoraria das condições de atuação do docente, e ainda, se possível (utopia), a mídia veicule a realidade da profissão, extinguindo a falsa ideia de como se essa fosse a profissão mais fácil de se trabalhar e que todos ganham bem. Afinal, esta é, inclusive, a posição de muitos pais que não têm conhecimento sobre o que é ensinar; urge também que a classe do professorado afirme com afinco: "sou profissional da educação", silenciando o velho e limitador jargão "eu dou aula".

Persp. online: hum. \& sociais aplicada., Campos dos Goytacazes, 20 (7), 11-27, 2017

seer.perspectivasonline.com.br 


\section{REFERENCIAS}

APPLE, Michael W. Educação e Poder. São Paulo: Artmed, 2002.

. Trabalho Docente e Textos: economia política das relações de classe e de gênero em educação. Porto Alegre: Artes Médicas, 1995.

ARANHA, Maria Lucia de Arruda. História da Educação. 2 ed. São Paulo: Moderna, 1996.

Filosofia da Educação. 3 ed. São Paulo: Moderna, 2006.

ARROYO, G. Miguel. Ofício de Mestre: Imagens e auto-imagens. 2 ed. Petropólis, RJ: Editora Vozes, 2000.

DELORS, Jacques (Org.). Educação: um tesouro a descobrir. 8 ed. São Paulo: Cortez, 2003.

ENGUITA, Mariano Fernandes. A ambigüidade da docência: entre o profissionalismo e a proletarização. Revista Teoria \& Educação. Porto Alegre, 1991, n 4, p. 41-60.

FREIRE, Paulo. Professora Sim Tia Não, cartas a quem ousa ensinar. São Paulo: Olho d'Água, 1997.

GENTILI, Pablo. Desencanto e Utopia: A educação no labirinto dos novos tempos. Petrópolis: Vozes, 2008.

LIBÂNEO, José Carlos. OLIVEIRA, João Ferreira de. TOSCHI, Mirza Seabra. Educação Escolar: políticas, estrutura e organização. São Paulo: Cortez, 2003.

LIBÂNEO, José Carlos. Democratização da Escola Pública: A pedagogia crítico-social dos conteúdos. 22 ed. São Paulo: Loyola, 2008.

. Pedagogia e Pedagogos, para quê? 12 ed. São Paulo: Cortez, 2010.

MINAYO, Maria Cecília de Souza. Pesquisa Social: teoria, método e criatividade. Petrópolis: Vozes, 1998.

NÓVOA, António. O passado e o presente dos professores. In: (Org.). Profissão Professor.

Portugal: Porto Editora, 1995. p. 13-34.

PARO, Vitor Henrique. Administração Escolar: introdução crítica. São Paulo: Cortez, 1986.

. Gestão Democrática da Escola Pública. 3 ed. São Paulo: Ática, 2010.

SACRISTÁN, Gimeno. Consciência e Ação Sobre a Prática como Libertação Profissional dos Professores. In NÓVOA, António (Org.). Profissão professor. Portugal: Porto Editora, 1995. p. 6392.

Persp. online: hum. \& sociais aplicada., Campos dos Goytacazes, 20 (7), 11-27, 2017 
SEVERINO, Antônio Joaquim. Metodologia do trabalho cientifico. São Paulo: Cortez, 1985.

TARDIF Maurice.; LESSARD, Claude. O trabalho docente: elementos para uma teoria da docência como profissão de interações humanas. 2 ed. Petrópolis, RJ: Vozes, 2005.

TOZONI-REIS, Marilia Freitas de Campos. Metodologia da Pesquisa. 2 ed. Curitiba: IESDE Brasil S.A., 2010. 